\title{
ESTIMATION OF LOS ANGELES AND MICRO DEVAL ABRASION VALUES FOR GNEISS AND GRANITE USING ANFIS APPROACH
}

\author{
Irina Pachoukova $^{1 *}$-Adekunlé A. Salami ${ }^{2}$ - Ayité S. Ajavon ${ }^{2}$ - Johnson Kodjo Ampah Christophe ${ }^{3}$ \\ ${ }^{1}$ Department of Civil Engineering, Ecole Nationale Supérieure d’Ingénieurs, University of Lome, Lome, Togo \\ ${ }^{2}$ Department of Electrical Engineering, Ecole Nationale Supérieure d'Ingenieurs, University of Lome, Lome, Togo \\ ${ }^{3}$ Geological Department, Faculty of Science, University of Lome, Lome, Togo
}

\begin{tabular}{l} 
ARTICLE INFO \\
\hline Article history \\
Received: 11.12 .2017$. \\
Received in revised form: 12.6 .2018$. \\
Accepted: 15.6 .2018$. \\
\hline Keywords: \\
Prediction \\
ANFIS \\
MLR \\
Los Angeles abrasion test (LA) \\
Micro Deval abrasion test (MD) \\
Rock drilling test \\
\hline DOI: httpildoiorg/10.30765/er.40.1.07
\end{tabular}

DOI: http://doi.org/10.30765/er.40.1.07

\section{Introduction}

The construction of important civil engineering structures (dams, power plants, buildings, bridges, roadways) requires the use of good quality materials (aggregates) to guarantee users safety. The main specification for the use of aggregates relates to their mechanical strength. The current tests of Los Angeles (LA) and Micro Deval (MD) evaluating the quality and durability of these aggregates are expensive, difficult and time-consuming. Our constant concern in this study is to reduce the relatively high costs of these tests by developing

\begin{abstract}
:
Gneisses and granites mechanical properties knowledge such as the Los Angeles and Micro Deval tests is very important for the engineer when designing and building civil engineering works. Laboratories test often performed to obtain Los Angeles and Micro-Deval values are expensive and time consuming. For this, the depths (parallel and perpendicular to the foliation planes) obtained during a rock drilling test will be used to estimate its Los Angeles and Micro Deval values. In this study, an ANFIS approach is used to estimate gneisses and granites Los Angeles and MicroDeval that have been compared to the Multiple Linear Regression method. For this purpose, we have used a database of a sample size of 80 to determine the parameters of the ANFIS and Multiple Linear Regression models, and a second sample of size 15 used for the validation tests. The results obtained show us that we can estimate the mechanical properties (Los Angeles and MicroDeval) of gneisses and granites with the ANFIS approach.
\end{abstract}

Adaptive Neuro-Fuzzy Inference System (ANFIS) models where input will include the depth values obtained during the rock drilling tests and out will give the Los Angeles Abrasion (LA) and the Micro Deval Abrasion (MD). The test consists of measuring the depth created by the drill in a rock for a fixed time (t). Thus the use of the ANFIS approach by Gokceoglu et al. [1] to predict the mechanical properties of rocks, by Aali et al. [2] to estimate the soil saturation coefficient and by Singh et al. [3] for the prediction of the deformation modulus of rocks, we believe that the mechanical properties of rocks, such as the Los Angeles

\footnotetext{
${ }^{*}$ Corresponding author. Tel.: (228)90030886

E-mail address: iguinhouya@univ-lome.tg
} 
Abrasion and the Micro Deval Abrasion, can be predicted with the ANFIS approach. The ANFIS combines the advantages of a neural network [4] and fuzzy logic [5]. In this study, we used the ANFIS approach and compared it to an approach based on the Multiple Linear Regression [6] for the prediction of the mechanical properties of rocks from the perforation depth resulting from a drilling test. The Los Angeles and Micro Deval tests respectively make it possible to determine the resistance to abrasion and attrition wear of the rocks in the presence of water $[7,8]$ and therefore the mechanical properties of the aggregates.

\section{Experimental investigation}

\subsection{Dataset}

In this study, the ANFIS approach and the MLR method are used to predict the mechanical properties of rocks including the Los Angeles and Micro Deval from the depths that represent the models input data. These depths are obtained during parallel, perpendicular and random perforations on gneisses and granites during the drilling test. Indeed, the aggregates most used in civil engineering work come from gneisses, granites in Togo. To achieve the objectives, we were interested in the gneisses of the structural unit of the Benin-Togolese plain and granites of the northern part of Togo, originating from the African croton [9] which is represented by 95 samples taken from the five (5) regions of Togo. We have a database with a total of 95 rock samples, 80 of which were used for learning process, 15 to the validation test.

The rock drilling test consists of perforating the gneiss and granites using a $6 \mathrm{~mm}$ drill with a speed of $550 \mathrm{rpm}$ under a load of $10 \mathrm{~N}$. After the $10 \mathrm{sec}$ perforation time, the depth created by the drill in a parallelepiped shaped rock sample (Figure 1) is measured by a slide caliper.
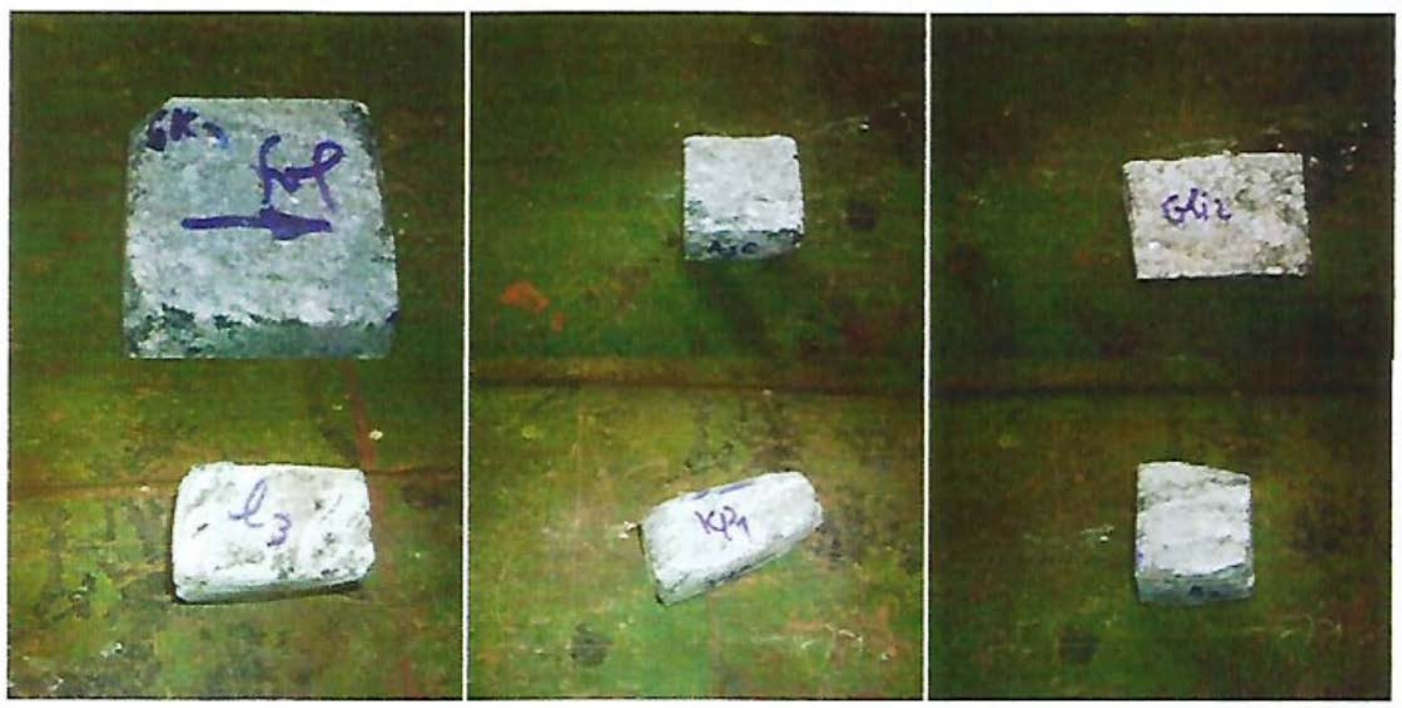

Figure 1. Samples prepared for the rock drilling test

To perform the perforation, a drill press CINCINNATI (Figure 2) was used to which a dynamometer was attached applying a drilling force of $10 \mathrm{~N}$. On each rock sample, five (05) perforations were produced in the foliation layers (both parallel and perpendicular plane) for gneisses and in two perpendicular planes for granites. By foliation we mean the set of parallel planes according to which the new minerals are crystallized. The average value of the five (05) depths of perforation obtained will serve as the input data of the models to be produced. Thus, we have the input data, which is the average depth of perforation parallel to the plane of foliation, which we will simply call depths of perforation parallel to the foliation plane (DPaFP) and the depths average of the perforation perpendicular to the foliation plane is also called in a simple way perforation depths perpendicular to the foliation plane (DPeFP). 


\subsection{Multiple linear regression}

The Multiple Linear Regression Model $[6,10]$ for two regresses $X_{1}$ and $X_{2}$ is given in (1),

$$
y=\beta_{0}+\beta_{1} x_{1}+\beta_{2} x_{2}+\varepsilon
$$

where $y$ represents the response, $\beta_{0}, \beta_{1}, \beta_{2}$ are called the regression coefficients, and $\varepsilon$ is a random error term.

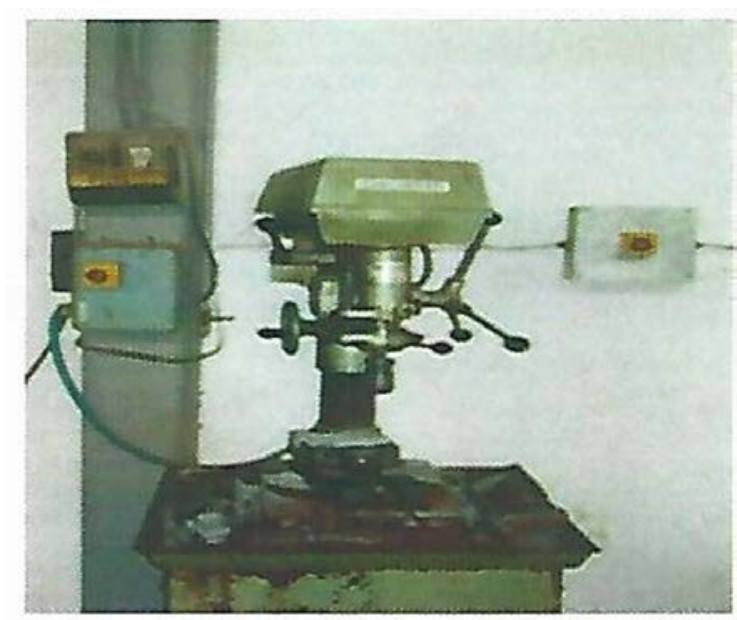

Figure 2. Drill Press CINCINNATI

\subsection{The adaptive neuro-fuzzy ANFIS}

The neuro-fuzzy system is a hybrid system that combines the techniques of fuzzy logic and neural networks [5, 6, 12 and 12].
We distinguish two great families of fuzzy systems [13], that of Mamdani and that of Takagi-Sugeno. Thus, the neuro-fuzzy systems are classified into two large families that are the Mamdani neuro-fuzzy system and the Takagi-Sugeno neuro-fussy system.

The Takagi-Sugeno neuro-fuzzy systems are most widely used [14], thanks to their universal approximation properties and the fact that they no longer require a defuzzification module as in the case of the Mamdani fuzzy system. One of the commonly used tools, based on the Takagi-Sugeno neuro-fuzzy system is ANFIS. The ANFIS is an adaptive Neuro-Fuzzy Inference System which consists of a five (5) layer MLP neuron network for which each layer corresponds to the realization of a step of a fuzzy inference system of type TakagiSugeno.

For simplicity, we assume that the inference system fuzzy with two inputs $\mathrm{x}$ and $\mathrm{y}$, and $\mathrm{z}$ as an output. Assume that the rule base contains two fuzzy Takagi-Sugeno rules (relations (3) and (4)).

Rule 1:

$$
\begin{gathered}
\text { IF } x \text { is A1 and } y \text { is B1 } \\
\text { THEN } z 1=p 1 x+q 1 y+r 1
\end{gathered}
$$

Rule 2:

IF $x$ is $\mathrm{A} 2$ and $y$ is $\mathrm{B} 2$

$$
\text { THEN } z 2=p 2 x+q 2 y+r 2
$$

The ANFIS has an architecture laid by five layers as shown in Figure 3 [14]:

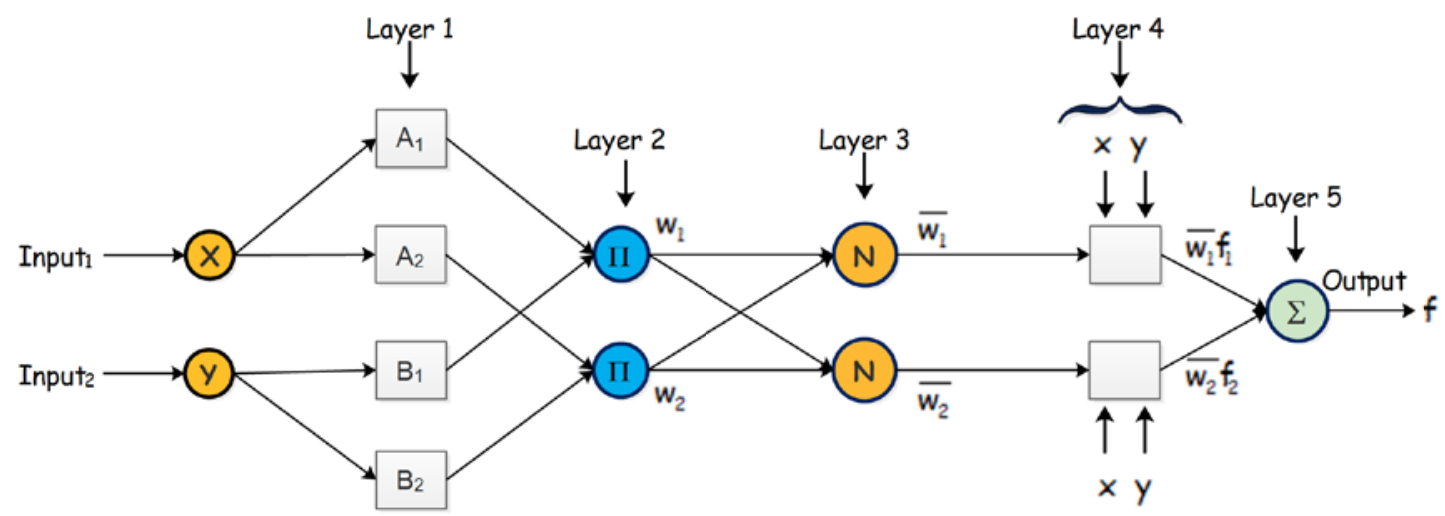

Figure 3. Architecture ANFIS 
Layer 1: this layer allows the fuzzification of the $x$ and $y$ inputs. Each neuron in this layer corresponds to a linguistic variable. The $\mathrm{x}$ and $\mathrm{y}$ entries are fuzzified by using membership functions of the linguistic variables $\mathrm{Ai}$ and $\mathrm{Bj}$, (usually their form are triangular, trapezoidal or Gaussian). For example, the relations (5) and (6) define the Gaussian membership function:

$$
\begin{aligned}
& \mu_{A_{i}}(x)=\exp \left[-\frac{1}{2} \frac{\left(x-\bar{x}_{i}\right)^{2}}{\sigma_{x_{i}}{ }^{2}}\right] \\
& \mu_{B_{j}}(y)=\exp \left[-\frac{1}{2} \frac{\left(y-\bar{y}_{j}\right)^{2}}{\sigma_{y_{j}}{ }^{2}}\right]
\end{aligned}
$$

where, $\mathrm{i}, \mathrm{j}=1.2$; and are the centers and $\sigma$ the width of the membership function.

The outputs of the first layer are given by the relations (7) and (8):

$$
\begin{aligned}
& x_{1, i}=\mu_{A_{i}}(x) \\
& y_{1, j}=\mu_{B_{j}}(y)
\end{aligned}
$$

Then, the values $\mu \mathrm{Ai}(\mathrm{x}), \mu \mathrm{Bj}$ (y) respectively represent the degree of belonging of value $\mathrm{x}$ to the set $A$ and y to the set $\mathrm{B}$.

Layer 2: each node corresponds to a fuzzy Tstandard (the T-standard operator makes it possible to achieve the equivalent of a Boolean "AND"). It receives the output of fuzzification nodes and calculates its output value thanks to the product operator (this operator is generally used but there are others: $\max , \min . .$.$) .$

The activation function of the neurons $i$ of the first layer is expressed by the relation (9) [5]:

$$
w_{i}=\min \left\{\mu_{A_{i}}(x), \mu_{B_{j}}(y)\right\}, i=1,2 ; j=1,2
$$

Layer 3: This layer normalizes the results provided by the previous layer according to relation (10). The results obtained represent the degree of involvement of the value in the final result [15]. The output of this layer can be written according to relation (10).

$$
\bar{w}_{i}=\frac{w_{i}}{\sum_{i=1}^{2} w_{i}}
$$

The outputs of this layer are called the normalized weights.

Layer 4: Each node of this layer is connected to the initial inputs. The result is calculated according to its input and a linear combination of the first order of the initial entries (Takagi-Sugeno approach).

The output of this layer is expressed by the relation (11).

$$
f_{i}^{4}=y_{i}=\bar{w}_{i} \times\left(p_{i} x_{1}+q_{i} x_{2}+r_{i}\right)
$$

where: $y_{i}$ is the output of the third layer; and $\rho_{i}, q_{i_{i}} r_{i}$ are the set of parameters designated under the name: "consequent".

Layer 5: it consists of a single neuron which calculates the sum of the signals of the preceding layer accordingly to relation (12):

$$
y=\sum_{i=1}^{2} y_{i}
$$

The ANFIS uses a hybrid learning process for the estimation of the premise and consequent parameters [1]. The hybrid algorithm splits learning process in two (02) independent stages: the first stage is the adaptation of learning weights, and the second one that of the adaptation of the nonlinear membership functions. This method is able to decrease the complexity of the algorithm, and at the same time increase learning time [16].

\subsection{Statistical indicators used for performance evaluation}

To assess the performance of the model, mean absolute percentage error (MAPE), root mean square error (RMSE), correlation coefficient $\left(R^{2}\right)$, variance account for (VAF) and relative percentage error (RPE), have been used in this study. In the following, a brief description of the considered statistical parameters is provided.

\subsubsection{Relative percentage error}

The RPE shows the percentage deviation between the predicted values $x_{i}$ and those obtained by 
measured values $\mathrm{y}_{\mathrm{i}}$ and its values ranging between $10 \%$ and $+10 \%$ which are usually considered acceptable. RPE is defined as:

$$
\operatorname{RPE}(\%)=100 \cdot\left(\frac{y_{i}-x_{i}}{y_{i}}\right)
$$

\subsubsection{Mean absolute percentage error}

The MAPE shows the mean absolute percentage difference between the predicted values and those attained by the measured values. The MAPE is calculated by $[3,4]$ :

$$
M A P E=\frac{1}{N} \sum_{i=1}^{N}\left|\frac{y_{i}-x_{i}}{y_{i}}\right| \cdot 100
$$

\subsubsection{Root mean square error}

The RMSE identifies model accuracy by comparing the deviation between the values achieved by the predicted values and those of measured data. The RMSE has always a positive value and it is calculated using equation (15) [4]:

$$
R M S E=\sqrt{\frac{1}{N} \sum_{i=1}^{N}\left(y_{i}-x_{i}\right)^{2}}
$$

\subsubsection{Correlation coefficient}

The $\mathrm{R}^{2}$ which indicates the strength of the linear relationship between the predicted values and the measured by [4]:

$$
R^{2}=\frac{\sum_{i=1}^{N}\left(x_{i}-\overline{x_{i}}\right)\left(y_{i}-\overline{y_{i}}\right)}{\sqrt{\sum_{i=1}^{N}\left(x_{i}-\overline{x_{i}}\right)^{2} \sum_{i=1}^{N}\left(y_{i}-\overline{y_{i}}\right)^{2}}}
$$

\subsubsection{Variance Account for}

The Variance Account For (VAF) was calculated using equation (17):

$$
\operatorname{VAF}(\%)=100 \cdot\left(1-\frac{\operatorname{Var}\left(y_{i}-x_{i}\right)}{\operatorname{Var}\left(x_{i}\right)}\right)
$$

with the Variance (Var) were given by equation (18).

$$
\operatorname{Var}(y)=\frac{1}{n} \sum_{i=1}^{n}\left(y_{i}-\bar{y}\right)^{2}
$$

\section{Results and discussion}

The comparison between the MLR and ANFIS models for the prediction of LA and MDE are made. Two variables, namely the foliation plane parallel perforation depth (DPaFP) and the perforation depth perpendicular to the foliation plane (DPeFP) from a drilling test, are used as input variables for each model. 80 measurement points are used to determine the parameters of each model. Each measurement point in Figures 4 and 5 has the following coordinates: (DPaFP, DPeFP, LA) or (DPaFP, DPeFP,MD).

Figures 4 and 5 also show us respectively the plane corresponding to the equation (19) of the model MLR for the prediction of LA obtained with an R2 of 0.855 and the plane corresponding to equation (20) of the MLR model for the prediction of MDE obtained with an R2 of 0.833 .

$$
\begin{gathered}
L A=3.286 D P a F P+0.655 D P e F P+20.329 \\
M D E=1.603 D P a F P+0.266 D P e F P+7.664
\end{gathered}
$$

The results obtained show that there is a strong correlation between LA or MD with DPaFP compared to DPeFP, which is explained by the high values of the weights assigned to DPaFP.

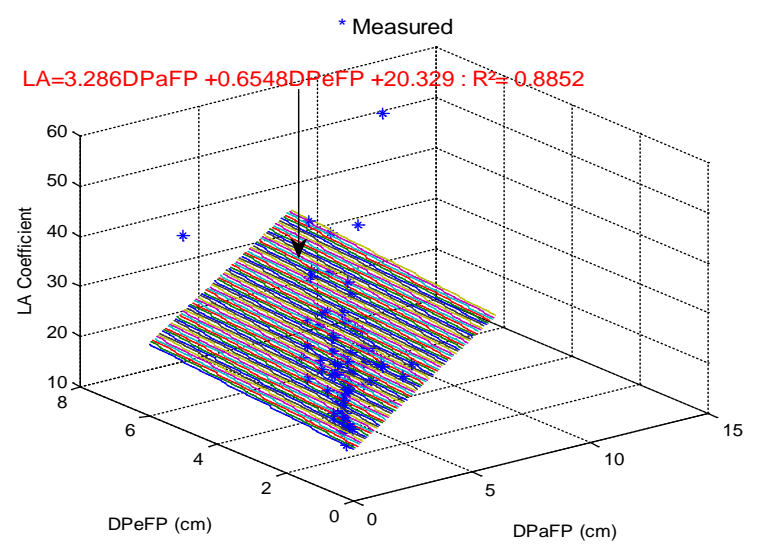

Figure 4. Result of LA prediction model using MLR 


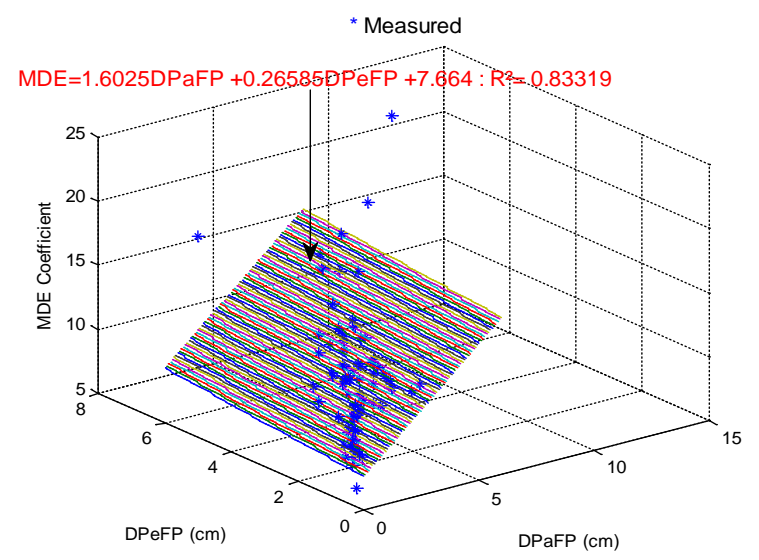

Figure 5. Result of MD prediction model using MLR

ANFIS models for LA and MD estimation are done according to the structure of Figure 6.

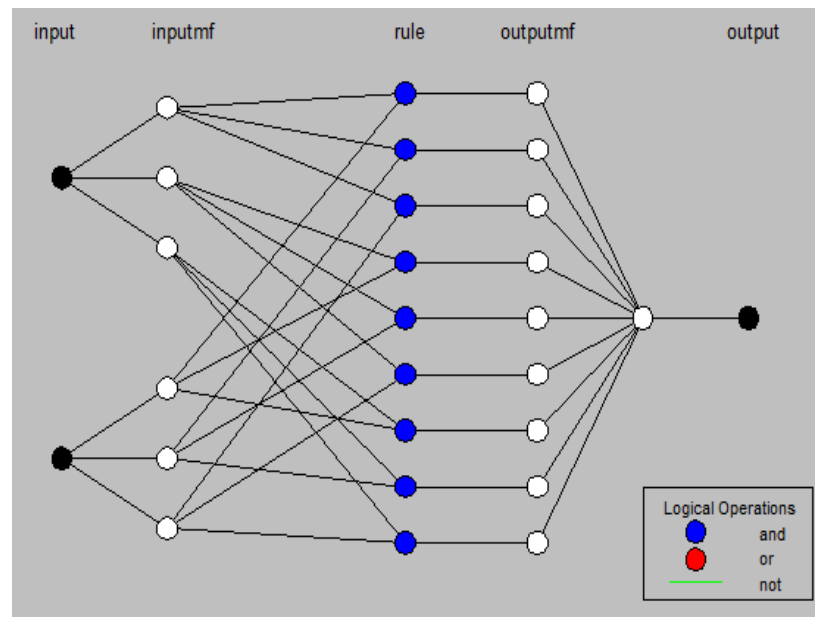

Figure 6. The ANFIS model structure for LA and MD prediction

To perform fuzzyfication entries, two membership functions (Gaussian and Bell) often cited in the literature [3] are used. Figures 7 and 8 present respectively the input variables of the ANFIS models with Gaussian and Bell membership functions.
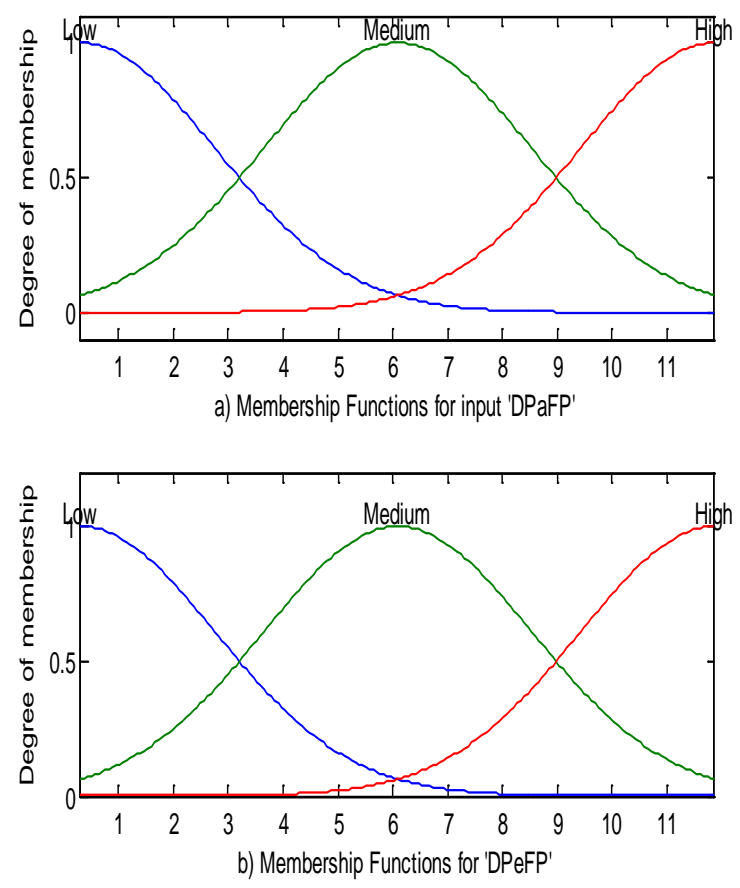

Figure 7. Gaussian membership function plot for input (a) 'DPaFP', (b) 'DPeFP',
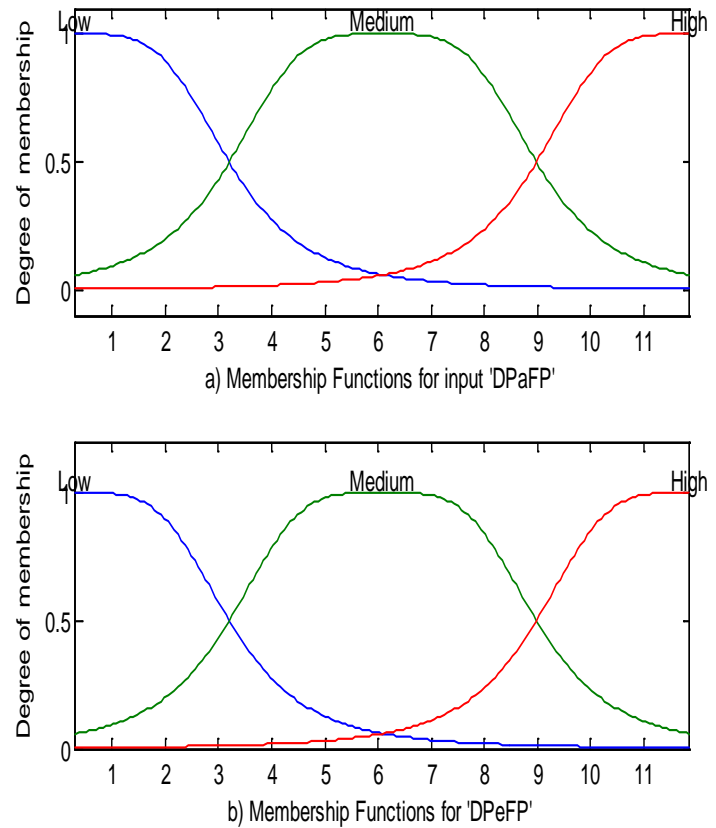

Figure 8. Bell membership function plot for input (a) 'DPaFP', (b) 'DPeFP',

For each type of membership function (Bell or Gaussian), the hybrid algorithm is applied to the 
membership function of each input. This hybrid algorithm uses the backpropagation method and the least squares method to obtain the optimal parameters of the ANFIS model. To execute this hybrid algorithm, the iteration number is set to 100 . Figures 9 and 11 show the RMSE learning process and validation error variations for the prediction of LA and MD, respectively, when the Bell membership function is used. . We can note on these two Figures (9 and 11) that RMSE errors during validation tests reach minimum values after 10th iteration more precisely at the 4th iteration for ANFIS LA prediction models and MD prediction.

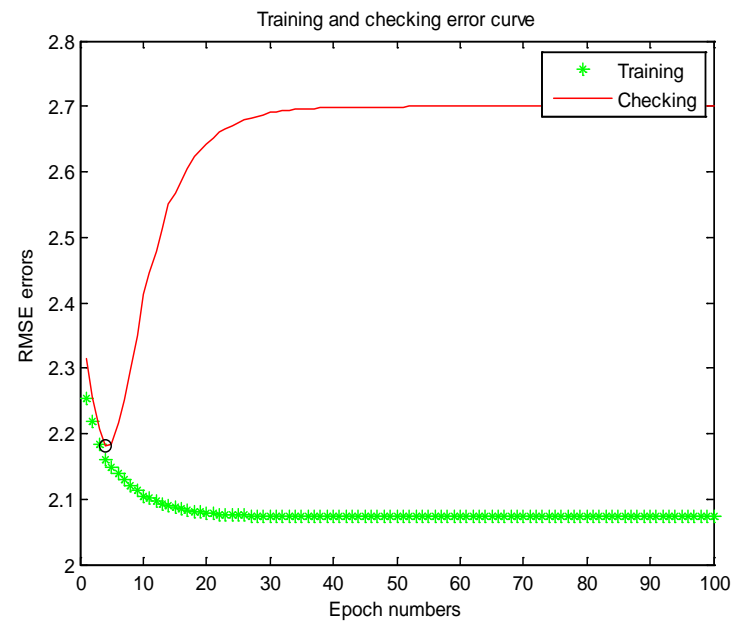

Figure 9. Training and checking error curve for $L A$ prediction using Bell membership function

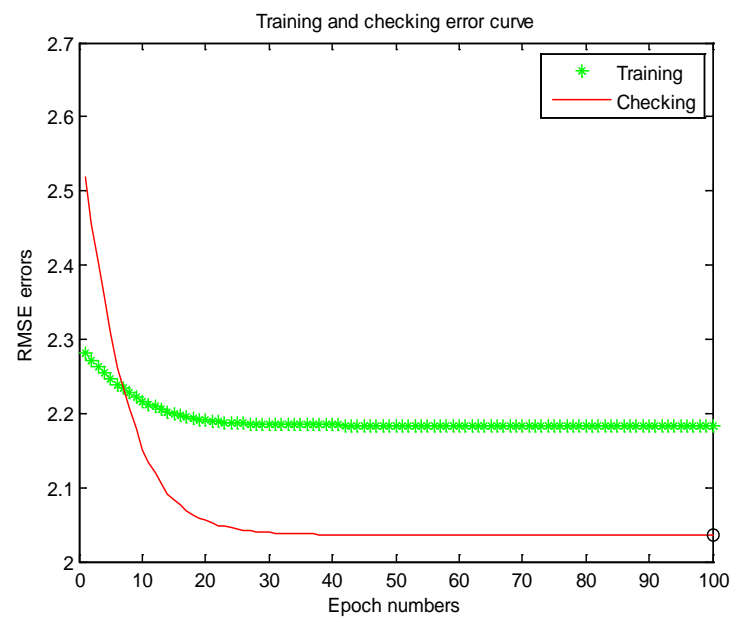

Figure 10. Training and checking error curve for LA prediction using Gaussian membership function

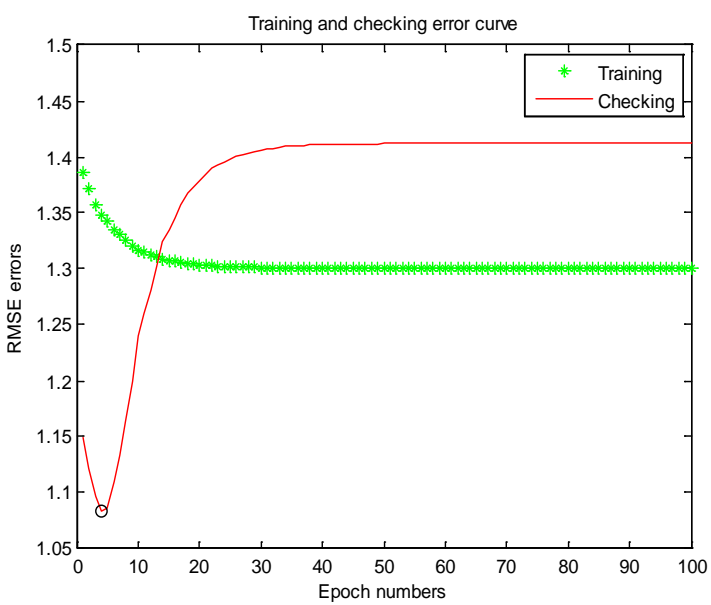

Figure 11. Training and checking error curve for MD prediction using Bell's membership function

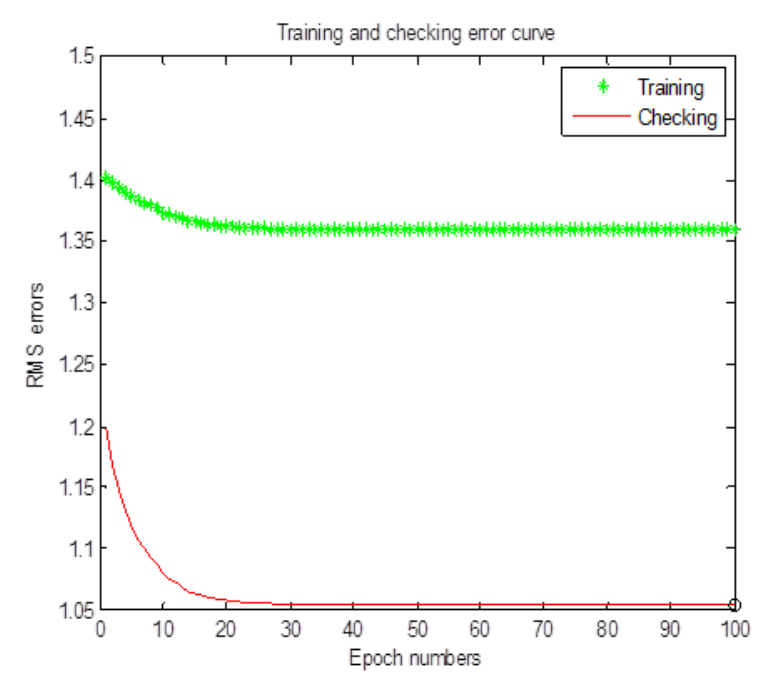

Figure 12. Training and checking error curve for $M D$ prediction using Gaussian membership function

On the other hand, from the curves of the RMSE errors of Figures 10 and 12 which show the learning process and validation results respectively for the prediction of LA and MD for a Gaussian membership function, we note minimal errors RMSE starting from Iteration 30.

To assess the performance of each model developed in this article, we calculated the five indicators whose formulas are presented in Section 4 of this article. Figures 13 and 14 present respectively the performances of the ANFIS prediction models of LA for a membership function of Bell and a 
Gaussian membership function. The results of Figures 13 and 14 show us that: the prediction model of LA by the ANFIS approach with the Bell type membership function is performed with an $\mathrm{R}^{2}$ of 0.946, an RMSE of 2.181, an MAPE of 7.144, an VAF of 66.095 against the ANFIS approach with the Gaussian type membership function realized with an $\mathrm{R}^{2}$ of 0.942 , an RMSE of 2.035, with an MAPE of 6.732 and an VAF of 75.33. It should also be noted that the MLR approach, using the equation (19), allows predicting LA during validation tests with an $\mathrm{R}^{2}$ of 0.952 , an RMSE of 2.205, with an MAPE of 7.312 and a VAF of 63.788. From the results visualized in Figures 13 and 14 we can conclude that the appropriate model to estimate LA is the ANFIS model using the Gaussian type membership function. To evaluate the appropriate model among the ANFIS model and the MLR model, Table 1 shows for each validation data, the prediction error (RPE) of the 15 cases of the ANFIS model predicts LA with a maximum RPE of $17.385 \%$ against a maximum RPE of $24.438 \%$ for the MLR model. Thus the ANFIS model of membership function of Gaussian input variables is the most appropriate for estimating LA.

Respectively, figures 15 and 16 present the performances of the ANFIS prediction models of MD for a membership function of Bell and a Gaussian membership function. The results shown in Figures 15 and 16 indicate that the prediction of $\mathrm{M}$ by the ANFIS approach with the membership function using the type Bell is carried out. The $\mathrm{R}^{2}$ was about 0.933, with an RMSE of 1.083, an MAPE of 7.407, and a VAF 65.205 against the ANFIS approach. Meanwhile, the Gaussian membership function gave an $\mathrm{R}^{2}$ of 0.924 , an RMSE of 1.054, an MAPE of 7.623, and a VAF of 70.905. Note also that the MLR approach using equation (20) allows MD to be predicted during validation tests with an $\mathrm{R}^{2}$ of 0.924 , an RMSE of 1.173 , an MAPE of 8.465 and a VAF of 52.372. From the results visualized on Figures 15 and 16 we can conclude that the appropriate model for estimating MD is the ANFIS model using a Gaussian type membership function. To evaluate the appropriate model among the ANFIS model and the MLR model, Table 1 shows for each validation data, the prediction error (RPE) for the 15 cases of the ANFIS model predicts MD with a maximum RPE of $23.326 \%$ against a maximum RPE of $24.041 \%$ for the MLR model. Thus, the ANFIS model of membership function of the Gaussian input variables is the most appropriate for estimating MD.

Gaussian membership function versus Measured LA values respectively the input variables of the ANFIS models with Gaussian and Bell membership functions.

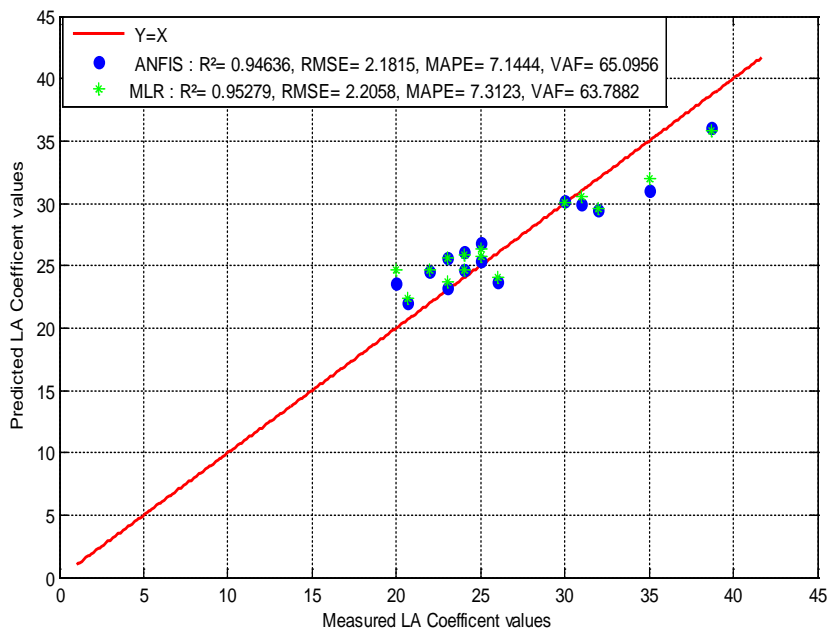

Figure 13. Scatter plots of predict LA values using Bell membership function versus Measured LA values

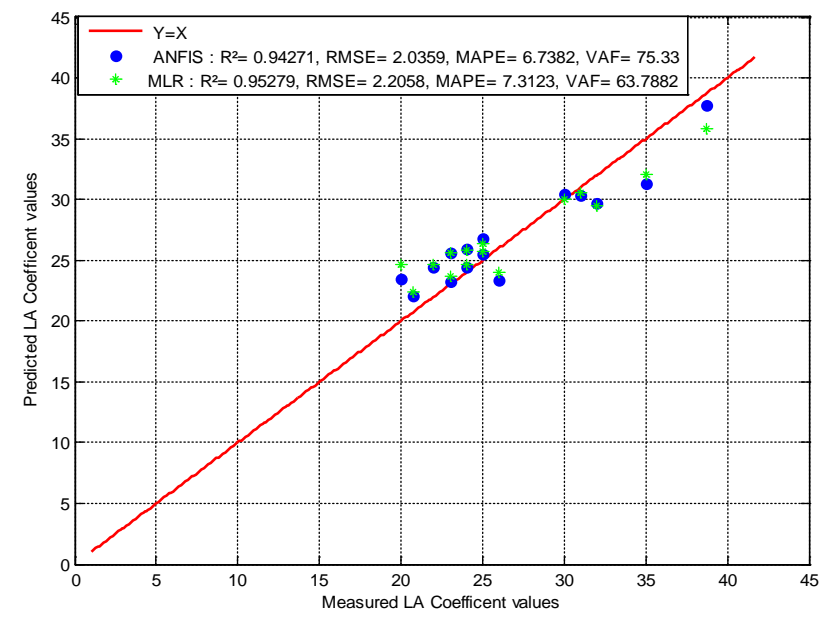

Figure 14. Scatter plots of predict LA values using Gaussian membership function versus Measured LA values 


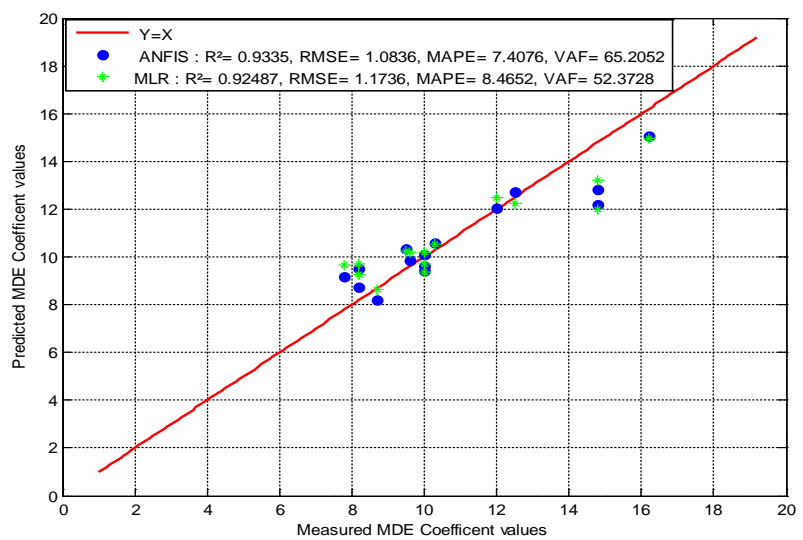

Figure 15. Scatter plots of predict MDE values using Bell membership function versus Measured MD values

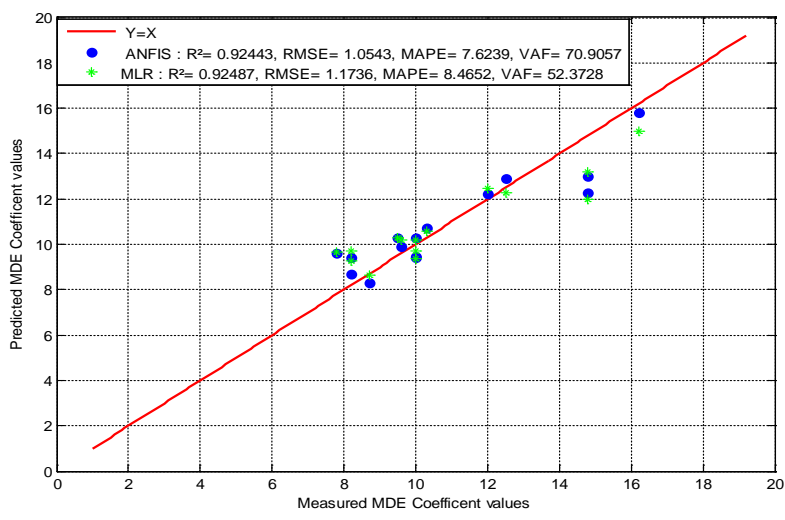

Figure 16. Scatter plots of predict MDE values using Gaussian membership function versus Measured MD values

Table 1. Observed and predicted values of LA from ANFIS and MLR models along with RPE

\begin{tabular}{|l|c|c|c|c|c|c|c|}
\hline \multirow{2}{*}{$\begin{array}{c}\text { Number of } \\
\text { sample }\end{array}$} & DPaFP & DPeFP & $\begin{array}{c}\text { LA } \\
\text { observed }\end{array}$ & $\begin{array}{c}\text { LA } \\
\text { predicted } \\
\text { by MLR }\end{array}$ & $\begin{array}{c}\text { RPE by } \\
\text { MLR }\end{array}$ & $\begin{array}{c}\text { LA } \\
\text { predicted } \\
\text { by ANFIS }\end{array}$ & $\begin{array}{c}\text { RPE by } \\
\text { ANFIS }\end{array}$ \\
\cline { 2 - 7 } & $\mathrm{cm}$ & $\mathrm{cm}$ & & & $\%$ & & $\%$ \\
\hline 1 & 3.00 & 2.20 & 32.0 & 29.523 & 7.742 & 29.721 & 7.121 \\
\hline 2 & 1.09 & 1.10 & 22.0 & 24.657 & 12.079 & 24.418 & 10.990 \\
\hline 3 & 2.14 & 0.90 & 20.0 & 24.688 & 23.438 & 23.477 & 17.385 \\
\hline 4 & 2.20 & 1.20 & 25.0 & 25.713 & 2.851 & 25.510 & 2.042 \\
\hline 5 & 3.60 & 2.40 & 31.0 & 30.573 & 1.379 & 30.301 & 2.255 \\
\hline 6 & 1.00 & 1.42 & 23.0 & 25.650 & 11.521 & 25.611 & 11.351 \\
\hline 7 & 1.20 & 1.07 & 24.0 & 24.631 & 2.628 & 24.417 & 1.739 \\
\hline 8 & 2.80 & 2.40 & 30.0 & 30.049 & 0.163 & 30.449 & 1.497 \\
\hline 9 & 1.35 & 1.40 & 24.0 & 25.813 & 7.556 & 25.976 & 8.234 \\
\hline 10 & 2.80 & 3.00 & 35.0 & 32.020 & 8.513 & 31.257 & 10.695 \\
\hline 11 & 4.60 & 3.8 & 38.7 & 35.828 & 7.422 & 37.715 & 2.546 \\
\hline 12 & 0.51 & 0.53 & 20.7 & 22.404 & 8.234 & 22.097 & 6.750 \\
\hline 13 & 1.60 & 0.80 & 26.0 & 24.005 & 7.671 & 23.362 & 10.146 \\
\hline 14 & 1.24 & 1.60 & 25.0 & 26.398 & 5.594 & 26.800 & 7.200 \\
\hline 15 & 0.73 & 0.87 & 23.0 & 23.666 & 2.895 & 23.258 & 1.121 \\
\hline
\end{tabular}


Table 2. Observed and predicted values of MD from ANFIS and MLR models along with RPE

\begin{tabular}{|l|c|c|c|c|c|c|c|}
\hline \multirow{2}{*}{$\begin{array}{c}\text { Number of } \\
\text { sample }\end{array}$} & DPaFP & DPeFP & $\begin{array}{c}\text { MD } \\
\text { observed }\end{array}$ & $\begin{array}{c}\text { MD } \\
\text { predicted } \\
\text { by MLR }\end{array}$ & $\begin{array}{c}\text { RPE by } \\
\text { MLR }\end{array}$ & $\begin{array}{c}\text { MD } \\
\text { predicted } \\
\text { by ANFIS }\end{array}$ & $\begin{array}{c}\text { RPE by } \\
\text { ANFIS }\end{array}$ \\
\cline { 2 - 7 } & $\mathrm{cm}$ & $\mathrm{cm}$ & & & $\%$ & & $\%$ \\
\hline 1 & 3.00 & 2.20 & 14.8 & 11.987 & 19.007 & 12.265 & 17.130 \\
\hline 2 & 1.09 & 1.10 & 8.2 & 9.717 & 18.494 & 9.400 & 14.636 \\
\hline 3 & 2.14 & 0.90 & 7.8 & 9.675 & 24.041 & 9.619 & 23.326 \\
\hline 4 & 2.20 & 1.20 & 10.0 & 10.172 & 1.719 & 10.268 & 2.681 \\
\hline 5 & 3.60 & 2.40 & 12.0 & 12.467 & 3.892 & 12.211 & 1.759 \\
\hline 6 & 1.00 & 1.42 & 9.6 & 10.205 & 6.306 & 9.919 & 3.327 \\
\hline 7 & 1.20 & 1.07 & 10.0 & 9.698 & 3.023 & 9.478 & 5.224 \\
\hline 8 & 2.80 & 2.40 & 12.5 & 12.254 & 1.965 & 12.887 & 3.094 \\
\hline 9 & 1.35 & 1.40 & 9.5 & 10.266 & 8.067 & 10.288 & 8.293 \\
\hline 10 & 2.80 & 3.00 & 14.8 & 13.216 & 10.704 & 13.022 & 12.017 \\
\hline 11 & 4.60 & 3.80 & 16.2 & 14.976 & 7.553 & 15.800 & 2.469 \\
\hline 12 & 0.51 & 0.53 & 8.7 & 8.649 & 0.587 & 8.317 & 4.398 \\
\hline 13 & 1.60 & 0.80 & 10.0 & 9.371 & 6.286 & 9.425 & 5.755 \\
\hline 14 & 1.24 & 1.60 & 10.3 & 10.558 & 2.501 & 10.720 & 4.076 \\
\hline 15 & 0.73 & 0.87 & 8.2 & 9.252 & 12.832 & 8.706 & 6.174 \\
\hline
\end{tabular}

\section{Conclusion}

In order to reduce the cost and time used to obtain the results of the Los Angeles and Micro Deval tests in the laboratory we have used the ANFIS model. The input parameters of the model are the obtained results during the drilling test. This test is quick and less expensive. This ANFIS model is compared to an MLR model.

The results showed that the performance of the ANFIS model far exceeds that of MLR.

For instance, the ANFIS, LA yields an $\mathrm{R}^{2}$ of 0.946, an RMSE of 2.181, an MAPE of 7.144 and a VAF of 66.095; meanwhile that of the MLR gives an $\mathrm{R}^{2}$ of 0.952 , an RMSE of 2.205 , an MAPE of 7.312 and a VAF of 63.788.

However, MD provides an $\mathrm{R}^{2}$ of 0.933 , an RMSE of 1.083, an MAPE of 7.407, and a VAF 65.205 against the ANFIS approach, meanwhile that of the MLR gives an $\mathrm{R}^{2}$ of 0.924 , an RMSE of 1.173 , with an MAPE of 8.465 and a VAF of 52.372.

The advantages of the ANFIS model lies in the fact that it is a combination of two approaches that are the neural approach and the logic one. The hybrid algorithm that is used to determine the optimal parameters of the model. The obtained ANFIS models can be used to estimate LA and M aggregates in Togo and elsewhere in the world.

\section{References}

[1] Gokceoglu C., Yesilnacar E., Sonmez H., Kayabasi A.: A neuro-fuzzy model for modulus of deformation of jointed rock masses, Comput. Geotech. 31 (2004), 375383.

[2] Aali K.A., Parsinejad M., Rahmani B.: Estimation of saturation percentage of soil using multiple regression, ANN, and ANFIS techniques, Comput. Inf. Sci. 2 (2009), 3, 127-136.

[3] Singh R., Kainthola A., Singh T. N.: Estimation of elastic constant of rocks using an ANFIS approach, Elsevier, 12 (2012), 4045.

[4] Dechemi N., Benkaci T.: Modélisation des débits mensuels par les modèles conceptuels et les systèmes neuro-flous, Journal of Water Science, 16 (2003), 4, 408-418.

[5] Abdallah B.: Commande Prédictive Non Linéaire en Utilisant Les Systèmes NeuroFlous et les Algorithmes Génétiques, Mémoire Magister en Automatique, option Commande et Identification Des Systèmes Dynamiques, 2013, 28-53.

[6] De Forest, D. K., Brix, K. V., Tear, L. M., \& Adams, W. J.: Multiple Linear regression (MLR) models for predicting chronic aluminum toxicity to freshwater aquatic 
organisms and developing water quality guidelines, Environmental Toxicology and Chemistry, DOI:10.1002/etc 3922,(2017), 20.

[7] Norme française: NFP18-573 1990, Granulats - Essai Los Angeles.

[8] Norme française: NFP18-572 1990, Granulats - Essai d'usure Micro Deval.

[9] Sylvain J.P., Aregba A., Collart J., Godonou K.S.: Carte géologique du Togo à 1/500000, Direction générale des Mines, de la Géologie et du Bureau Nationale de Recherches Minières, Lomé, 1986.

[10] Brix, K. V., DeForest, D. K., Tear, L., Grosell, M., \& Adams, W. J.: Use of Multiple Linear Regression Models for Setting Water Quality Criteria for Copper: A Complementary Approach to the Biotic Ligand Model, Environmental Science \& Technology, 51 (2017), 9, 5182-5192.

[11] Singh T. N., Kanchan R., Verma A. K., Saigal K.: A comparative study of ANN and Neuro-fuzzy for the prediction of dynamic constant of rockmass, J. Earth Syst. Sci., 114 (2005), 1, 75-86.

[12] Ma Wei, Ma Fei: Modeling and experimental study on drilling rig anti-jamming valve with $B P$ neural network, Engineering Review, 36 (2016), 2, 99-106.

[13] Jang, J. R.: Neuro-Fuzzy Modeling, IEEE, 83(1995), 3, 378-405.

[14] Jang, J. R.: ANFIS: Adaptive-Ne work-Based Fuzzy Inference System, IEEE, 23 (1993), 3, 665-68.

[15] Özgür K.: Suspended sediment estimation using neuro-fuzzy and neural network approaches, HSJ, 50 (2005), 4, 683-696.

[16] Tahmasebi P., Hezarkhani A.: Application of adaptive neuro-fuzzy inference system for grade estimation; case study, Sarcheshmeh porphyry copper deposit, Kerman, Iran, Aust. J. Basic Appl. Sci., 4 (2010), 3, 408-420. 